\section{TORSION OF THE GREAT OMENTLM.}

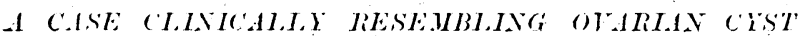
IITII TIISTED PEDICLE.

$13 \mathrm{Y}$

J. PRESC O'T'T HEDLEY, M.B., M.C.C.NTar., F.R.C.S.ENG.,

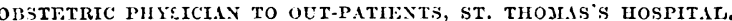

Torsios of the great omentum is a rare condition, and the. reported cases are still less than one hundred in number. I an recording this case partly on account of its rarity and partly because the signs and symptoms very closely resembled those produced by the twisting of the pedicle of an ovarian cyst.

I never suspected that I was dealing with any thing but an ordinary ovarian cyst with a twisted pedicle until I examined the patient under the anacsthetic before operating. Then it was clear that there was no large eyst, but an irregular clastic mass. I thought it possible that these signs could be accounted for by the rupture of the main cyst of an adenoma of the ovary.

\section{IIT:(1)!?!}

The patient was a womm, aget 35, who hat been married for nineteen years, and had had five children. Her general liealth had been sood. She had had a right inguinal hernia for six years, and liad worn a truss, which had controlled it properly. Jf ever the patient got up without first putting on the truss the hernia always appeared. The mass was as large as her doubled fist. During the six years it has not altered in consistency or size ; it could alway's be replaced easily and quickly, and was mever tender or painful. 'The only discomfort associated with the hernia was a dragging pain in the epigastric region if the contents of the sac were allowed to remain down for any lengtl of time. In August, 1909, the patient was operated upon for right hydronephrosis. The loin incision was used, and conseguently the peritoneal cavity was not opened.

\section{The Present Illness.}

The patient dated her present illness from Jul. 23rd. 1910 onc week hefore armission to st. Thomas's Hospital. That day she was doin's her washing, and as she turnerl to so out of the doni', which was on her left hand, she trod on the copper stick. tried to save herself from falling with her right hand against the open door, but fell heavily on to the stone foor full length on hei left side. At the time slie felt shaken but did not notice anything detinitely wrong. On the following two days she felt "out of sorts and shaky."

On July 26th, between 1 and 2 p.m., she had an attack of abiominal pain. It was not localized, and was of a colicky mature. J)uring that day she hial about a dozen attacks of the sime lind.

()n July 27 th, at 1 a.m., she hat an attack of most excruciating pain in the abdomen, accompanied by shivering and sweating. This was followed by other exactly similar attacks at intervals of about ten minutes. A doctor was called, who tieated her for colic.

The attacks of pain coutinned throush that and the two following davs (July 28 th and 29 th) at gradually increasing intervals until arhinssion. There had been no diarrhoea or romiting, and the bowels had acted regularly.

The patient was admitterl to st. Thomas's Hospital on fuly 3jth, under the care of Dr. Tate, who kindly transferied her to m! charge.

\section{On Firamination.}

The abilominal wall was held tense and was very tender, especially in its lower part. Alowe the symphysis pubis there was an area dull on perentision which extended half-way up to the umbilicus. On raginal examination the nterus was retroverted, and in front of it a hard masss could be felt extending into the left fornix ; the aldomen was too tender to permit of a thorough bimanual examination. The temperature was 101 and the pulse-rate 98 . The diagnosis of ovarian cyst with twisted pedicle was made.

Thie next day (July 31st) the temperatuie har fallen to 100 and the pulse-rate to 92 , but as the pain still continued, overation was thonglis sidvable.

$$
\text { Entrination under the Anacsthetic. }
$$

An abromins t timour was felt rising from the pelvis to a point half-way up to the umbilicus. On vaginal examination there conld lie felt lying in front and to the left of the retrorerted uterus a solid clastic tumour of irregular shape, which extended into the abdoment. and could be easily grasped between the two hands.

Operation.

The left rectus muscle was displace:l ontwards and the peritoneum divided. There was blood-stained fluid in the peritoneal cuvity and a hard granular mass was seen immediately heneath the lower part of the incision. The tumour was attacher to the anterior ablominal wall by recent adhesions, over an area which extended upwards for $3 \mathrm{in}$. from the symphysis p'lbis. The adhesions were easily broken down, and then the mass was seen to be the twisted and matted omentum; the lower part was attached by the same type of adhesions to the uterus, left broad ligament, and the iliac and pelvic colons. There was no comnexion whatever with the hernial sac, which was on the right side. After separating the adhesions, the tumour was brought out of the wound.

The omentum had twisted about a vertical axis, its right enge having travelled to the left anteriorly and its left edse to the right posteriorly; there were three complete turns. The mass was engorged and oedematous for the most part, but the amount of swelling varied in different parts, according to their relations to the axis of torsion. An attempt was made to untwist the omentum, but it was found to be impossible, partly on account of the turns being adherent to one another, but chiefly, I think, from the amount and unevenuess of the swelling. "Removal was therefore undertaken. At the top of the twist the omentum was therefore undertaken. At the top of the twist the omentum was cord-like and about the thickness of one's little finger, but passing out to the left from this was a sheet of normal omentum
about 2 in. in width; the twisterl part and the latter were ligatured and the mass removed. After removal the $m$ covered transverse colon was seen crossing the abdomen. The abdominal cavity was closed in the usual way.

\section{The Parts Remored.}

The specimen was preserved by the Kaiserline methor and drawn afterwards (Fig. 1 ), and now weighs $9 \mathrm{oz}$., and measures $10 \mathrm{in.}$ in length. Its ip)er and the lower parts differ willely in character another.

The upper part is a hard fibrous mass, 5 in long, 4 in. wide, and 1.: in. thick; it is twisted on a vertical axis throush five halfturns, and is so matted and thickened that it camnot be untwisted.

In some places the surface is dark grer, and in others the colour of normal omentum. On looking letween the turns of the twist and into the folds on the surface it is seen to bo dark real fiom ensorsement with blood Tite grey areas on the sur face were dark red when the tumour was remored.

The appenrance of this part of the mass and the increase of tibrous tissue suggest that there had been chronic thickening in the omentum before the twist occurred.

Iicroscofical examination shows the presence of a larse imount of fibrous - tissue and thrombosis of the ressels.

The drawing, which is a view from the

front, shows the direction of the twist. The cut pediclo is circular, and measures half an inch in diameter. The lower part where it is continuous with the upper is twisted an thickened, but elsewhere has the appearance of norma omentum, and can be separated into its layers.

\section{fite'r-IIistory.}

The patient malle an minterrupted recovery, the temperature remained normal after the operation, and there was remarkably little pain. The wound healed by ffrst intention, and the patient was able to get up on the twelfth day, and leare the hospital on the twentieth after operation.

I saw her about three months after discharge. The herni: had not coms down since the operation, and her general condition was excellent.

The recorded cases of torsion of the great omentum are still comparatively few, and I can find references to only 93 cases, although the condition was first observed and described nearly thirty years ago.

I have been able to obtain details of 73 cases from the paper's published by Cornu and Pinches,' Lejars," Picquet," and other's.

Amongst these 73 there either was or had been a hernia in 60, and in almost all of them the hernia was present at the time of the operation.

In the remaining 13 there was no history or evidence of a hernia having existed. 
Picquet says that in nearly all the cases collected by Cernezzi rotation had occurred between two fixed points, the upper being where the twisted mass became continuons with the omentum, and the lower where the omentum had become attached by old adhesions.

The lower attachment was usually near the hernial sac. In the 60 cases associated with hernia of which I have details, the twisted mass of omentum was fixed below in 52-in 48 it was actually in the hernial sac or attached to its neck, in 3 the adhesion was to bowel, and in 1 to the Fallopian tube.

Old adhesions were absent in only 8 of the cases. In my case the mass was not connected in any way with the hernia, nor were there any oll aclhesions.

It appeared from the examination of the specimen removed that an omental tumour had been produced by the matting and chronic thickening of that part which had from time to time descended into the sac.

The normal omentum above such a tumour would constitute a long and thin pedicle, and thus the conditions favourable to rotation of the tumonr wonld be produced. In only a small proportion of the cases has the rotation been attributed to any particular exciting cause: repeater attempts to reduce the hernia have been considered responsible in a few cases, and violent efforts in some others.

In my case the patient's fall, thres days before the onset of abdominal pain, appears to have been the immecliate cause of the rotation of the tumour.

The diagnosis in cases of torsion of the omentum is extremely difficult, and has, I believe, been made correctly on one occasion only. The reasons for the difficulty are that the condition is extremely rare. and the signs and symptoms very closely resemble those producer? by other conditions.

The only treatment is by operation: it may be possible in certain cases to spread out the twisted omentum. but in the great majority this cannot be done, and consequently it is necessary to remove the part below the point of rotation.

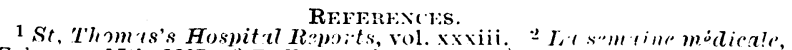

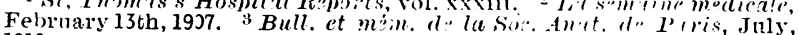
1910 .

\section{A CASE OF ANTENATAL PNELMONIA.}

$$
13 \mathrm{x}
$$

\section{ALEX. T. I. MACDONALD, M.B.,} CH.B.GILAS:.

TATK HOUSE-SIRGFON, GLASGOW MATHINITY AND WOMHN'S HOSPIT.I.

The following case, which by the courtesy of 1)r. J. M. Munro Kerr I am allowed to report, presents several features of unusual intcrest from the point of view of the effect of the disease in the proinct of renception.

Mrs. S., aged 29, pregnant for the fifth time and apparentiy at term, was admitted to hospital on the evening of Siptember 17th, 1910, suffering from acute lohar pueumonia in its early stages.

The pregnancy had rum a normal c wize tuntil three days before admission, when the patient felt fererish and complained of sore throat and of general malaise. Her husband noticerl at the time that her voice was husky. Early next morning she shivered and had severe stabbing prin below the left breast and over the left base, her breathing becoming rapid, and painful on deep inspiration. There was some sickness during the day. She was seen in the evening by her medical attendant, who diagnosed lobar meumonia. $\Lambda$ s she was at term and could not be nursed satisfactorily at bome he ordered term and could not be nurs
lier removal to hospital.

On admission the face was flushed, the respirations rapis and painful (44 per minute), pulse 124 . The tongue was re and dry on the dorsum, and covered at the edges with a thick rellowish-white fur. The bowels were constipated. She had a short, painful cough, accoingenied by scanty, tenacious spit, rusty at first, later more bloodr. ('n microscopic examination Fraenkel's Ifiplococons pmenominc was found in large numbers, in clusters and in fairly long chains. Some were intracellular in the polymoiphonuclear lencocrtes. The phrsical signs were those of an early pneumonia, in volving the lower lobe of the left lung. Morement of that side was restricted. Vccal resonance and fremitus were slightly increased. The percussion note had a tympanitic quality orerthe left lung, in front and behinil, and tine crepitations were heard over the lower lobe. The risht limg was the seat of some hronchitis. The second sumd of the berti wats sifter and less sharply defined than normally. The urine was of a deep amber colour, specific gravity 1025, and was acid in reaction. It contained a trace of slbumen, and chlorides were diminished.

Jater tubular breathing was heard over the lower axillar. region, and finally the whole of the lower lobe of the left lun became consolidated, tubularity being extremel- well marked. Four days after admission there was lancinating pain over the right lung at its base, and a consolidated patch was found to be present at the extreme base, but there was no further extension.

The degree of prexia was moderate throughout, the temperature reaching 103 on the fifth day of the disease, and falling to ture reaching 103 on the fifth day of the disease, and falling to
98.6 by the following morning. Coincidently with the extension at the right base it rose to $100.6^{\circ}$, and remained approximatel. at that level until the twelfth day, when it again reachei normal. The patient was free from pain on the ninth day, and the sputum by this time was muco-purulent in character. Subseguent progress was satisfactory

Labour came on spontaneously on september 19th, that is two dars after almission, and, after a short second stage, thie patient was delivered naturally at $10.30 \mathrm{p}$.n. of a living female child, whose length was 19 inches and weight $6 \mathrm{lb}$. There was considerable physical emberrassment during the labour, and the patient was freeir stimuleted and oxyen was administered at intervals.

The child was feeble, but crier soon aftcr birth. It was slightly cranosed during the night, but this improved in the course of the following morning. Later the breathing became laboured, and increasing cyanosis was noticeable. There were only one or two attempts at conghing. Respiration guickly became sighing, and mucus accumulated in the larrnx; cleati occurred twenty-eight hours after delivery.

A post-mortem examination was performed by Dr. A. M. Kemmedy, pathologist to the hospital. The right lung generally was more bulky than the left, aud the upper and lower folses ani the posterior half of the middle lobe was consolidated from pneumonia in the stage of red hepatization; the anterior portion
of the middle lobe merely showed engorsement. In the left of the middle lobe merely showed engorgement. In the left lung marked congestion of the lower lobe was present, while
the upper lobe showed numerous min'te beads of interstitial emphisema, and one larger bulla at the anterior margin under the pleir'a. The heart was of normal appearance. The peri cardium contained an excess of blood-tinged fluid and a small quantity was also present in the abdominal cavity. The liver and kidners showed marked venous congestion. The spleen was sliglitive enlarged, and somewhat soft and diffient. Films was slighitly enlarged, and somewhat soft and diffuent. Films
from the lung were stained, and in them large numbers of from the lung were stained, and in them large numbers of
pneumococci were present, similar in monphological character; to those in the mother's sputum.

From the advanced inflamniatory changes present.in the fetal lungs so soon after birth it is probable that the pnemunic condition originated in utero.

Had the pueumonia arisen from insufflation of liquor amnii or vaginal discharge during delivery, it would have had a lobular rather than a lobar distribution. Here there was certainly no insufflation of morbicl material, rupture of the membranes preceding the birth of the child by twent: minutes only.

As is well known, pneumonia is sometimes associated with lesions in other parts of the body, pointing to the existence of a blood infection at some stage of the disease. In this case the diplococcus, present in the maternal blood, was apparently transmitted to the fetus throngh the placenta. The presence of the organism has been demonstrated in such cases in the uterine sinuses, as well as in the fetal portion of the placenta, and passage has been observed in animals (Foa and Bordoni-Lffreduzzi). To allow of transmission of the organism it is probable that some lesion of the placenta must be present, or that the placenta must be damaged by the toxic action of the maternal blood.

Ballantyne ${ }^{1}$ says that the fetal lungs are not frequently affected in pneumococcic infections. When they are, lesions of other parts are commonly found--for example, of the pleura. pericardium, or peritoneum. The organisa has been demonstrated in the exudates found in these cavities, as well as in the blood, and in the liver and spleen (Carbonelli, Netter, and others). Indeed, the power:s of resistance in the fetus seem comparable to those of certain moderatily susceptible animals, in which a septicaemic condition is the chief result of experimental incenlation, localized lesions being less common sequelae."

When the organism does settle down in the fetal ling, however, it is likely to find a suitable nidus, bearing in mind the def ctive blood supply before tl ese establishment of respiration. The lung then receives but a scanty supply of blood from the pulmenary artery, inost of the blood passing into the aorta by the ductus arteriosus without entering the lungs. T'he blood which does reach the lungs is somewhat impure, consisting mostly of the return flow from the head. Moreorer, the function of the lungs is in abcrance, and in common with other tissues 